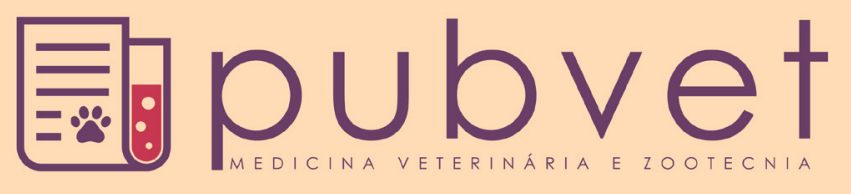

HTTP://DX.DOI.ORG/10.22256/PUBVET.V11N7.689-693

\title{
Hérnia incisional após ovariohisterectomia em fêmea canina
}

\author{
Emanuelle Bortolotto Degregori ${ }^{*}$, Gabriele Maria Callegaro Serafini² Mariana Roman $^{3}$
}

${ }^{1}$ Acadêmica do curso de Medicina Veterinária da Universidade Regional do Noroeste do Estado do Rio Grande do Sul, Departamento de Estudos Agrários (DEAg). Ijui-RS, Brasil.E-mail: emanuelle.bortolotto@gmail.com

${ }^{2}$ Professora do curso de Medicina Veterinária da Universidade Regional do Noroeste do Estado do Rio Grande do Sul, Departamento de Estudos Agrários (DEAg)). Íjui-RS, Brasil.E-mail: gabriele.serafini@unijui.edu.br

${ }^{3}$ Academica do Curso de Medicina Veterinária da Universidade Regional do Noroeste do Estado do Rio Grande do Sul. Departamento de Estudos Agrários (DEAg). Ijui-RS,BrasilE-mail: mah.roman@hotmail.com

RESUMO. O objetivo deste trabalho é relatar o caso de uma canina diagnosticada com hérnia incisional em local previamente incisado para realização de ovariohisterectomia. Após 30 dias da castração, o animal foi atendido apresentando aumento de volume na região retro umbilical do abdome e secreção serosanguinolenta pelos pontos. A paciente foi encaminhada para correção cirúrgica, onde se observou sutura com linha de pesca e indícios de erro de técnica. Após reavivamento das bordas da ferida, remoção do tecido fibroso e lavagem do local, procedeu-se com o fechamento da cavidade abdominal seguindo os princípios básicos da celiorrafia.

Palavras chave: Hérnia incisional, herniorrafia, técnica cirúrgica

\section{Incisional hernia after ovariohysterectomy in female canine}

\begin{abstract}
The objective of this paper is to report the case of a canine diagnosed with incisional hernia at a previously incised site for ovariohysterectomy. After 30 days of castration, the animal was treated with an increase in volume in the umbilical region of the abdomen and serosanguinolent secretion through the surgical stitches. The patient was referred for surgical correction, where suture was observed with fishing line and indications of technical error. After reviving the wound borders, removing the fibrous tissue and washing the site, the abdominal cavity was closed, following the basic principles of celiorraphy.
\end{abstract}

Keywords: Incisional hernia, herniorraphy, surgical technique

\section{Hernia incisional después de ovariohisterectomía en hembra canina}

RESUMEN. El objetivo de este trabajo es relatar el caso de una canina diagnosticada con hernia incisional en local previamente incisado para realización de ovariohisterectomía. Después de 30 días de la castración, el animal fue atendido presentando aumento de volumen en la región retro umbilical del abdomen y secreción serosanguinolenta a través de los puntos. La paciente fue encaminada para corrección quirúrgica, donde se observó sutura con línea de pesca e indicios de error de técnica. Después del reavivamiento de los bordes de la herida, remoción del tejido fibroso y lavado del local, se procedió con el cierre de la cavidad abdominal siguiendo los principios básicos de la celiorrafia.

Palabras clave: herniorrafia, protrusión, técnica quirúrgica

\section{Introdução}

Hérnias incisionais são formadas quando uma cavidade fechada cirurgicamente se rompe, podendo ser de forma aguda ou crônica. É mencionada uma incidência de a 1 a $11 \%$ em pacientes humanos, e de mais de $16 \%$ em grandes animais, o que varia de acordo com a abordagem 
cirúrgica, fatores preestabelecidos e estado clínico geral do paciente (Slatter, 2007). A prevalência em cães e gatos é menos comum, tendo um valor de referência de $6,5 \%$ (Slatter, 2007).

Hérnias incisionais advêm de forças excessivas que atuam na incisão abdominal ou de uma resistência insuficiente de fixação da ferida suturada (Slatter, 2007). Material de sutura com falha mecânica, infecção, desnutrição, redução na síntese proteica, perda de proteína de forma exagerada, fibroplasia retardada devido à administração de altas doses de corticosteroides e aumento na pressão intra-abdominal são algumas etiologias que irão predispor a deiscência da ferida cirúrgica (Nelson and Couto, 2015). Erro técnico no procedimento cirúrgico é a razão mais comum em casos agudos (Slatter, 2007) Edema e inflamação são sinais de cura modificada da ferida cirúrgica, sendo que qualquer ferida que apresentar estes sinais deve ser inspecionada (Fossum, 2014, Slatter, 2007).

O reparo no tratamento de hérnias incionais tem como objetivos: reestabelecer o suporte estrutural, estabelecer cobertura eficiente dos tecidos moles, aprimorar aparência estética e reduzir a morbidade e incapacitação dos pacientes (Mazzocchi et al., 2011). A técnica e o material a ser utilizado na herniorrafia são de suma importância, pois este deve ser resistente o suficiente para evitar as recidivas (Gianlupi and Trindade, 2004). O presente trabalho tem como objetivo relatar o caso clínico de uma fêmea canina diagnosticada com hérnia incisional após castração, submetida a reparo cirúrgico.

\section{Metodologia}

Um canino, fêmea, da raça Collie, com sete anos de idade e $27 \mathrm{~kg}$ foi atendida no Hospital Veterinário da UNIJUİ. Segundo o proprietário, a paciente havia sido submetido a ovariohisterectomia há cerca de 30 dias e apresentou sangramento na ferida cirúrgica no pós-operatório. Ao exame clínico, observou-se aumento de volume na região retro umbilical e secreção serosanguinolenta através dos pontos, mas sem sinal de dor local mediante palpação. Foi realizada coleta de sangue para avaliação de hemograma, o qual apresentou aumento dos neutrófilos não segmentados. Nos demais aspectos avaliados não houve alterações. A partir do histórico e exame clínico o animal foi diagnosticado com hérnia incisional e encaminhado para correção cirúrgica.
Para a anestesia foi administrada medicação pré-anestésica composta por acepromazina 0,05 $\mathrm{mg} / \mathrm{kg}$ e morfina $1 \mathrm{mg} / \mathrm{kg}$ por via intramuscular. Posteriormente, realizou-se a indução com propofol $4 \mathrm{mg} / \mathrm{kg}$ por via intravenosa, intubação orotraqueal e manutenção anestésica com isofluorano diluído a $100 \%$ de $\mathrm{O}_{2}$. A anestesia epidural foi realizada com lidocaína $1 \mathrm{ml} / 4 \mathrm{~kg}$ e ao final da cirurgia, como fármacos auxiliares, utilizaram-se dipirona $25 \mathrm{mg} / \mathrm{kg} \mathrm{SC}$ e meloxicam $0,2 \mathrm{mg} / \mathrm{kg} \mathrm{SC}$.

Para o procedimento cirúrgico, posicionou-se o animal em decúbito dorsal e realizou-se a antissepsia de toda região abdominal, previamente tricotomizada. Foram removidos os pontos de pele, que eram em padrão isolado simples com linha de pesca e realizou-se uma incisão mediana retroumbilical de pele e subcutâneo, sendo que no subcutâneo não foram observados pontos. Nesse momento observou-se a cavidade aberta, com bordas arredondadas da ferida cirúrgica e presença de fibrose (Figura 1). Notou-se a ausência de órgãos herniados, os quais, provavelmente, foram reduzidos pela ação da gravidade ao posicionar o animal.

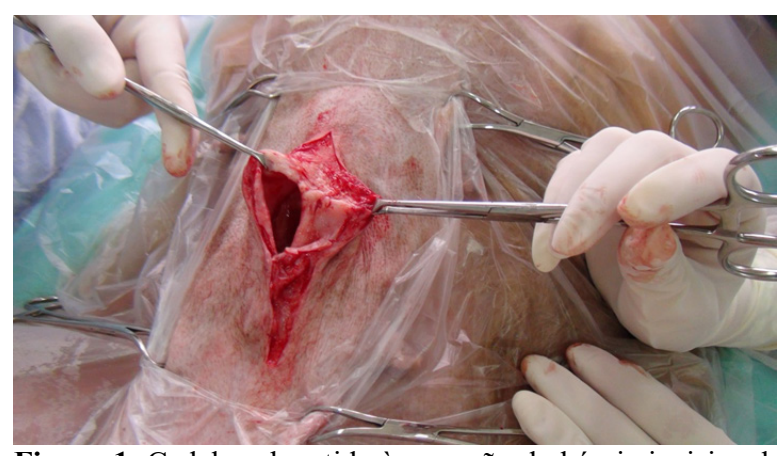

Figura 1. Cadela submetida à correção de hérnia incisional. Nessa etapa do procedimento, os pontos de pele já haviam sido removidos e a incisão de pele e subcutâneo efetuada. Observou-se, nesse momento, que a incisão prévia da cavidade abdominal não havia sido cicatrizada. Apresentava bordas arredondadas e presença de fibrose no local.

Percebeu-se, ainda, que a ferida cirúrgica da cavidade havia sido suturada com linha de pesca de grosso calibre em padrão contínuo, a qual se encontrava apenas de um lado da borda (Figura 2). Remove-se tal sutura (Figura 3) e ampliou-se a incisão para inspecionar a cavidade, assim como as ligaduras dos pedículos ovarianos e coto uterino.

Posteriormente, realizou-se remoção de um fragmento de cada borda da incisão, assim como do tecido fibroso no local. Efetuou-se a lavagem do local com $\mathrm{NaCl} 0,9 \%$ e seguiu-se com a síntese. Para a celiorrafia realizaram-se pontos em Sultam, 
com fio mononáilon 0 . No subcutâneo, sutura em Zig-Zag, com categute 2.0 e pele, pontos isolados simples com mononáilon 3.0. Durante o pósoperatório $\mathrm{o}$ animal foi mantido com antibioticoterapia com cefalexina $30 \mathrm{mg} / \mathrm{kg}$, BID, por sete dias, dipirona $25 \mathrm{mg} / \mathrm{kg}$, BID, por três dias e meloxican $0,1 \mathrm{mg} / \mathrm{kg}$, SID, por quatro dias.

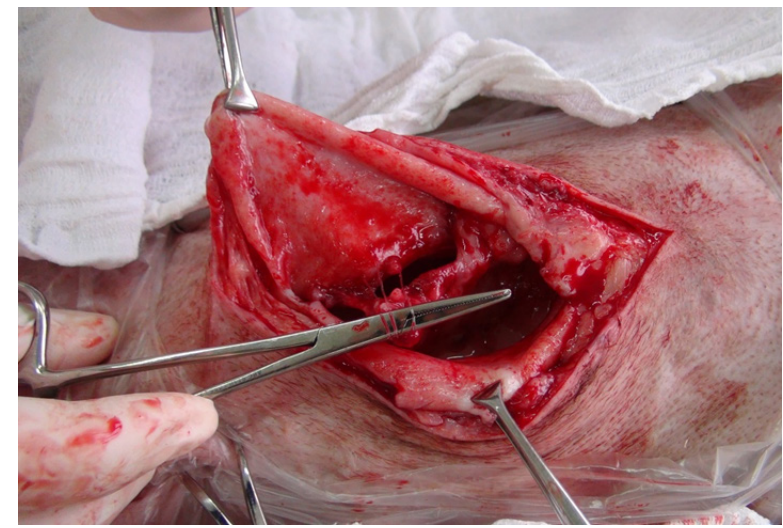

Figura 2. Cadela em procedimento de reparo de hérnia incisional. Notar a linha de pesca utilizada na celiorrafia quando o animal foi submetido à ovariohisterectomia anteriormente.

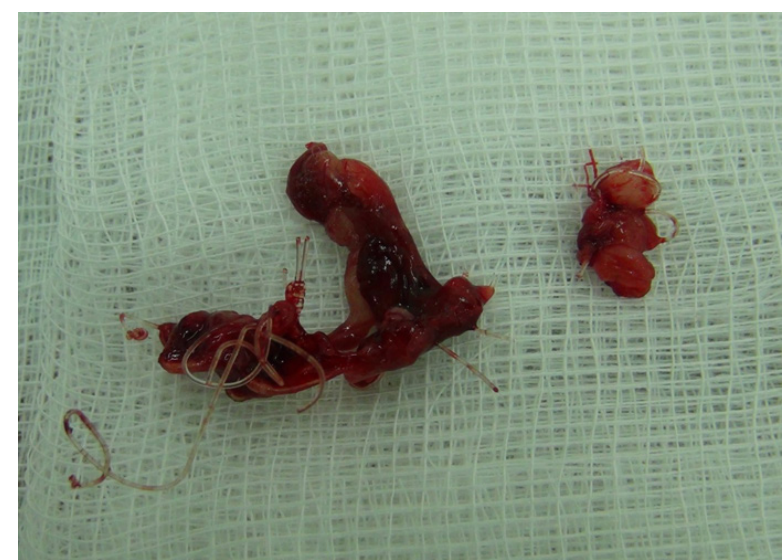

Figura 3. Linha de pesca de grosso calibre utilizada em uma cadela submetida a ovariohisterectomia, a qual, posteriormente, apresentou hérnia incisional

\section{Resultados e Discussão}

Hérnias incisionais agudas ocorrem habitualmente nos primeiros sete dias após o procedimento cirúrgico, já hérnias crônicas são observadas após a primeira semana ou até anos depois da cirurgia (Slatter, 2007). Em um estudo realizado por Slatter (2007), as hérnias ocorreram com maior constância entre o $5^{\circ}$ e $9^{\circ}$ dia de pósoperatório em cães e entre o $5^{\circ}$ e $7^{\circ}$ dias em gatos, sendo um período superior ao descrito por Slatter (2007), mas que foram consideradas agudas, já que o período de tempo foi semelhante. No presente caso, o proprietário não soube relatar há exatos quantos dias o aumento abdominal ventral surgiu, mas levando em conta que o animal foi castrado há 30 dias, que houve sangramento permanente pela linha de incisão durante esse tempo e que o tutor demorou para procurar atendimento, acredita-se que essa hérnia seja classificada como aguda também.

Pressão intra-abdominal causada por dor, tecido adiposo entre as bordas de sutura, material de sutura desapropriado, infecção, tratamento crônico por esteroides e cuidados falhos no pósoperatório são considerados fatores de risco em casos agudos (Chevrel and Rath, 2000, Slatter, 2007). Para hérnias crônicas, o principal fator determinante é a infecção profunda (Slatter, 2007). No caso descrito, acredita-se que a hérnia incisional tenha sido causada devido ao material de sutura inadequado, sendo este a linha de pesca, além de possível falha nos cuidados de pósoperatório, como restrição de exercícios.

Todos os fios usados na sutura são considerados corpos estranhos ao organismo, por isso, quando for efetuada a escolha devem ser levadas em conta as características físicas e a interação biológica do fio ao tecido (Van Winkle $\mathrm{Jr}$ and Hastings, 1972). Raramente, a escolha do fio é a única causa da herniação, desde que o tamanho seja adequado para o paciente (Slatter, 2007).

Cirurgiões tendem a escolher fios de sututra desapropriadamente grandes, o que resulta em reação tecidual maior, quantidade excessiva de material estranho na ferida e alteração na estrutura do tecido a ser suturado (Boothe, 1993). Acreditase que quanto mais grosso seja o fio, mais difícil fica de amarrar o nó com segurança, logo, no caso relatado, é possível que tenha sido um dos fatores determinantes para a ocorrência da hérnia incisional, considerando que o fio da "linha de pesca" foi julgado como grosso demais.

Em um estudo realizado por Rahal et al. (1998), onde foram comparadas reações teciduais com linha de pesca (poliamida) em formalina e autoclavadas com fio de náilon cirúrgico em ratos, foi observado no exame histopatológico que no $5^{\circ}$ e $15^{\circ}$ dia, quando utilizada linha de pesca em formalina houve inflamação aguda predominantemente neutrofílica, macrófagos, mastócitos e necrose concentrando-se especialmente ao redor do implante. Já no grupo onde foi utilizada linha de anzol autoclavada, no $5^{\circ}$ dia apresentou ao histopatológico intensa reação inflamatória aguda com predomínio de neutrófílos, raros macrófagos, mastócitos e fibroblastos, além de um tecido fibroso jovem que 
contornava o implante. Já no $15^{\circ}$ dia foram constatadas as mesmas alterações, porém com intensidade menor. A reação, quando foi utilizado fio de náilon cirúrgico no $5^{\circ}$ dia de pós-operatório, apresentou predominantemente infiltrada celular mononuclear e presença de fibroblasto, já no $15^{\circ}$ as lesões regrediram. Como referido por Boothe (1993), a reação tissular ao redor do fio de náilon cirúrgico é discreta, fato que cabe também à linha de pesca. Nesse sentido, os autores desse relato salientam a importância da esterilização e diâmetro do fio e usá-lo de forma asséptica para os procedimentos cirúrgicos, motivo o qual pode ter contribuído para o caso em questão.

Em um estudo de testes in vitro foi observado que apenas polidioxanona e náilon monofilamentar eram seguros no padrão interrompido com três laços quadrados. Já em suturas contínuas, os nós quadrados requerem um ou dois nós a mais para serem considerados seguros. Se a sutura será feita com pontos interrompidos ou contínuos, ou se a celiorrafia for feita em uma ou duas camadas não é significativo na formação da hérnia. O que realmente importa é que a camada resistente precisa ser incorporada na sutura, sendo que elas devem conter a fáscia reta externa com, no mínimo, $5 \mathrm{~mm}$ de borda para se obter segurança (Slatter, 2007). Na paciente relatada, observou-se que a sutura utilizada foi em padrão contínuo, aparentemente incorporando parede abdominal e subcutânea ao mesmo tempo e pouca borda na sutura, levando a ruptura da mesma.

Casos de evisceração, pela deiscência são mais frequentes em animais que possuem hérnias incisionais agudas. $\mathrm{O}$ omento e ligamento falciforme são os primeiros a protruir, após isso, os intestinos. A mutilação dos órgãos é bastante corriqueira, caso as vísceras fiquem expostas por um curto período de tempo. O resultado é perda sanguínea grave e sepse, que acaba levando o animal a um estado de choque (Fossum, 2014, Slatter, 2007). No paciente em questão, foi observado apenas o aumento de volume na região abdominal ventral e secreção serosanguinolenta através dos pontos, mas a evisceração poderia ter sido o próximo passo, visto que a pele e o tecido subcutâneo eram as únicas estruturas íntegras que sustentavam os órgãos herniados.

Sinais clínicos como edema, inflamação, tumefação, a qual geralmente é macia e indolor (a menos que haja infecção ou disfunção do órgão), e exsudato serosanguinolento requerem diagnóstico e reparo precoces (Slatter, 2007). O sintoma de dor não é frequentemente observado incialmente, porém pode ocorrer devido a esforço ou atividade intensa. Ao longo do tempo, quando a hérnia aumenta de volume, o paciente passa a ter o sintoma de dor, principalmente ao movimento, tosse ou quando realiza esforços demasiadamente. Sinais de vômito, constipação e dor intensa sugerem encarceramento ou estrangulamento visceral e se faz necessário o tratamento cirúrgico de emergência (Millikan, 2003). No caso clínico descrito, o animal não apresentava esses sinais compatíveis com encarceramento, o que foi comprovado durante a cirurgia, pois ao incidir a pele e subcutâneo o conteúdo já se encontrava reduzido para a cavidade abdominal.

Casos de hérnias agudas devem ser reparados com reconstrução musculofacial primária, caso o tecido esteja viável para que não haja tensão em demasia. Tecido e gordura desvitalizados devem ser removidos entre as bordas, sendo que o desbridamento é contraindicado, a menos que as bordas da ferida estejam inadequadas ou o tecido necrosado. Isso se deve, ao fato que, quando é realizado o desbridamento a ferida volta para a fase de substrato, o que acaba prolongando o ganho de resistência, além de criar trauma desnecessário no tecido e espalhar a contaminação (Slatter, 2007). Nesse caso, por haver fibrose nas bordas da incisão e sobre a fáscia muscular, optouse por remover tanto a fibrose, quanto um fragmento em cada borda para evitar a sua inserção na sutura, podendo assim levar a uma nova deiscência. Como a camada removida foi relativamente fina, não foi notado qualquer sinal de tensão na sutura.

Segundo Slatter (2007), como a maioria das hérnias incisionais são fechadas e ocorrem em consequência de erro técnico, a maioria dos pacientes possui um prognóstico excelente após ter-se realizado o reparo de maneira correta. Já em pacientes com sepse e contaminação peritoneal o prognóstico é considerado desfavorável. As complicações pós-operatórias que estão associadas à herniorrafia abdominal são seroma, hematoma, dermatite, infecção, dor e deiscência e evisceração da ferida. Esses sinais não foram presenciados no caso em questão, sugerindo que a intervenção cirúrgica foi bem sucedida, tanto porque não havia sinais de infecção no local dos pontos, como porque foram seguidos os princípios cirúrgicos para celiorrafias, como fios e diâmetros adequados e inclusão das bainhas externas e 
internas na sutura com margem de no mínimo 5 $\mathrm{mm}$.

\section{Conclusão}

A hérnia incisional do caso em questão ocorreu devido ao uso e condições inapropriadas do material de sutura, assim como possível erro de técnica. Nesse sentido, a reintervenção cirúrgica foi necessária para remoção do fio anterior, reavivamento das bordas e sutura adequada das bordas da ferida.

\section{Referências bibliográficas}

Boothe, H.W. 1993. Suture materials, tissue adhesives, staplers, and ligating clips. In: Slatter, D. (2 ${ }^{\mathrm{a} e d}$.) Textbook of small animal surgery. Saunders, Philadelphia..

Chevrel, J. P. \& Rath, A. M. 2000. Classification of incisional hernias of the abdominal wall. Hernia, 4, 7-11.

Fossum, T. W. 2014. Cirurgia de pequenos animais, 4 edn. Elsevier Brasil, São Paulo.

Gianlupi, Á. \& Trindade, M. R. M. 2004. Comparação entre o uso de fio inabsorvível (polipropileno) e fio absorvível (poliglactina 910) na fixação de prótese de polipropileno em correção de defeitos músculo-aponeurótico da parede abdominal. Estudo experimental em ratos. Acta Cir Bras, 19, 94-102.

Mazzocchi, M., Dessy, L. A., Ranno, R., Carlesimo, B. \& Rubino, C. 2011. “Component separation" technique and panniculectomy for repair of incisional hernia. The American Journal of Surgery, 201, 776-783.

Millikan, K. W. 2003. Incisional hernia repair. Surgical Clinics of North America, 83, 12231234.

Nelson, R. W. \& Couto, C. G. 2015. Medicina interna de pequenos animais. Elsevier Editora, Amsterdan.

Rahal, S. C., Rocha, N. S., Figueiredo, L. A. \& Iamaguti, P. 1998. Estudo comparativo das reações teciduais produzidas pela linha de pesca (poliamida) e fio de náilon cirúrgico. Ciência Rural, 28, 89-93.

Slatter, D. H. 2007. Manual de cirurgia de pequenos animais. Manole, São Paulo.

Van Winkle Jr, W. \& Hastings, J. C. 1972. Considerations in the choice of suture material for various tissues. Surgery, Gynecology \& Obstetrics, 135, 113-126.

Article History:

Received 2 March 2017

Accepted 28 March 2017

Available on line 11 June 2017

License information: This is an open-access article distributed under the terms of the Creative Commons Attribution License 4.0, which permits unrestricted use, distribution, and reproduction in any medium, provided the original work is properly cited. 